\title{
UM ESTUDO SOBRE O SWING A PARTIR DE VISÕES FORNECIDAS POR INTEGRANTES DE UMA COMUNIDADE VIRTUAL DE COMPORTAMENTO SEXUAL LIBERAL
}

\author{
UN ESTUDIO SOBRE SWING A PARTIR DE VISIONES PROPORCIONADO \\ POR MIEMBROS DE UNA COMUNIDAD VIRTUAL DE COMPORTAMIENTO \\ SEXUAL LIBERAL
}

\begin{abstract}
A STUDY ON SWING FROM VISIONS PROVIDED BY MEMBERS OF A VIRTUAL COMMUNITY OF LIBERAL SEXUAL BEHAVIOR
\end{abstract}

\author{
Fernanda GOMEZ ${ }^{1}$ \\ Paulo Rennes Marçal RIBEIRO ${ }^{2}$ \\ Vagner Sérgio CUSTODIO ${ }^{3}$
}

RESUMO: Este trabalho tem como objetivo diagnosticar visões sobre a sexualidade de pessoas com comportamentos sexuais liberais na comunidade dos swingers e suas opiniões acerca da motivação no meio sexual liberal, mais especificamente verificar o ânimo ou desânimo decorrente da prática do swing. Para isso utilizou-se um fórum de um website de comportamento sexual liberal que possui 16.589 perfis cadastrados, sendo 13.640 casais, 2.276 homens e 673 mulheres onde os membros espontaneamente discutiram essa questão. Foram ao todo 77 postagens que foram classificadas conforme a ocorrência, analisadas e comentadas qualitativamente. Buscamos entender as regras para a troca de casais, a questão do prazer no swing, a concepção de sexo liberal e a realização sexual com essa prática a partir do que disseram, nas postagens, os sujeitos participantes do fórum.

PALAVRAS-CHAVE: Comportamento sexual liberal. Sexo. Swing. Website.

RESUMEN: Este trabajo tiene como objetivo diagnosticar visiones sobre la sexualidad de personas con comportamientos sexuales liberales en la comunidad de swingers y sus opiniones sobre la motivación en el entorno sexual liberal, más específicamente para comprobar el estado de ánimo o desánimo resultante de la práctica del swing. Para ello, se utilizó un foro de un sitio web de conducta sexual liberal, que cuenta con 16.589 perfiles registrados, siendo 13.640 parejas, 2.276 hombres y 673 mujeres donde los miembros discutieron espontáneamente este tema. Un total de 77 publicaciones fueron clasificadas según la ocurrencia, analizadas y comentadas cualitativamente. Buscamos entender las reglas para el intercambio de parejas, la

\footnotetext{
${ }^{1}$ Universidade Estadual Paulista (UNESP), Araraquara - SP - Brasil. Mestranda no Programa de Pós-graduação em Educação Sexual na Faculdade de Ciências e Letras. ORCID: https://orcid.org/0000-0002-7105-1783. E-mail: gomez.fernanda@yahoo.com.br

${ }^{2}$ Universidade Estadual Paulista (UNESP), Araraquara - SP - Brasil. Professor Associado no Departamento de Psicologia da Educação e Docente dos Programas de Pós-graduação em Educação Sexual e Educação Escolar. Livre-Docente em Sexologia e Educação Sexual (UNESP). ORCID: https://orcid.org/0000-0002-1552-5702. Email: paulorennes@gmail.com.

${ }^{3}$ Universidade Estadual Paulista (UNESP), Rosana - SP - Brasil. Professor Assistente. Doutorado em Educação Física (UNICAMP). ORCID: https://orcid.org/0000-0002-1119-7246. E-mail: vagner.custodio@unesp.br
}

RPGE- Revista on line de Política e Gestão Educacional, Araraquara, v. 24, n. esp. 3, p. 1873-1883, nov. 2020. e-ISSN:1519-9029 
cuestión del placer en el columpio, el concepto de sexo liberal y realización sexual con esta práctica en base a lo que los participantes en el foro dijeron en los posts.

PALABRAS CLAVE: Comportamiento sexual liberal. Sexo. Swing. Sitio web.

ABSTRACT: This work aims to diagnose views on the sexuality of people with liberal sexual behaviors in the swingers' community and their opinions about motivation in the liberal sexual environment. For that, we have consulted a forum of a liberal sexual behavior website which has 16,589 registered profiles, being 13,640 couples, 2,276 men and 673 women, where members spontaneously discussed this issue. A total of 77 posts were classified according to the occurrence, analyzed, and commented on qualitatively. We seek to understand the rules for the exchange of couples, the question of pleasure in the swing, the concept of liberal sex and sexual fulfillment with this practice based on what the participants of the forum said, in the posts.

KEYWORDS: Liberal sexual behavior. Sex. Swing. Web site.

Esta pesquisa pretendeu verificar concepções sobre o comportamento sexual liberal em um grupo de praticantes de troca de casais, conhecidos como swingers, procurando identificar o que estimula essa prática e as reações por ela causadas em uma sociedade que ainda se constitui monogâmica e possuidora de um discurso pró fidelidade conjugal. Nesse contexto, os praticantes do swing buscam os espaços de troca de casais para realizarem fantasias que são contrárias ao formato tradicional monogâmico das relações estáveis.

\section{Revisão de literatura}

Swing é um termo da língua inglesa, sem tradução para o português, que se refere à troca de casais, um tipo de comportamento sexual liberal, cuja prática é geralmente considerada desviante e se opõe às percepções tradicionais de relacionamentos saudáveis (JENKS, 1998). O swing suscita estigmas, como considerar que seus praticantes aceitam "tudo" ou são libertinos, ou ainda promíscuos.

Carvalho e Vasconcelos (2013, p. 2) definem o swing como

a prática de relações sexuais entre casais, onde há a troca de parceiros(as) e o contato com experiências relativas a esse contexto. Com "outras experiências" se quer dizer todo o tipo de atividade da sexualidade que pode ser conferida levando em conta os parâmetros estabelecidos pelo casal. Desde a troca de parceiros, a relação entre pessoas do mesmo sexo, a relação com mais de um homem, ou com mais de uma mulher, ou mesmo a prática do voyeurismo (prazer em olhar), do exibicionismo (prazer em ser visto), ou do sexo no mesmo ambiente sem troca de parceiros. 
No entanto, alguns pesquisadores, como Jankowiak e Mixson (2008), argumentam que as noções de amor, intimidade e prazer sexual nas pessoas swingers são muito semelhantes às pessoas não liberais. Uma diferença entre os dois grupos é a dissociação entre o amor e o sexo, sendo que os swingers diferenciam esses dois relacionamentos e os não swingers correlacionam esses sentimentos com maior facilidade.

Alguns estudos (BERGSTRAND; SINSKI, 2010; WEID, 2010; WEID, 2012; JENKS, 1998) já discutem o tema e afirmam que o swing proporciona mais benefícios do que consequências negativas, não só para relação, mas também para os swingers enquanto indivíduos, buscando compreender como esse estilo de vida liberal pode ajudar nas relações amorosas. As alegações mais comuns são que a atividade fortalece o casamento e aumenta a percepção acerca da qualidade do mesmo; aproxima o casal emocional e sexualmente; melhora o desempenho sexual e aumenta a autoestima.

Nota-se que a prática do swing tem tido cada vez mais adeptos, por dois motivos: curiosidade e melhoramento da relação. Apesar de existir uma cultura popular, social e religiosa que impõe a ideia de que relação extraconjugal atrapalha, no caso do swing a lógica subverte a tradicional união monogâmica. $\mathrm{O}$ sexo fora do casamento não é considerado traição, e sim, ajuda a fortalecer o casal. Ao contrário de relações poliamorosas, o swing geralmente é praticado por casais heterossexuais com relações estáveis e os envolvimentos com outros indivíduos são definidos principalmente pela intimidade física, sem outros envolvimentos. Nessa perspectiva, casais swingers devem manter limites e uma comunicação aberta. Para ajudar a combater problemas de ciúme, por exemplo, os casais são guiados por regras acordadas para garantir que ocorra a troca somente da intimidade sexual, e não da intimidade romântica, ou seja, é proibido ter sentimento (BERGSTRAND; SINSKI, 2010; WEID, 2010; WEID, 2012; JENKS, 1998).

Para Fontoura Jr. (2015, p. 45), o swing

envolve a conjugalidade, o desejo de manutenção da família nuclear, princípios do amor romântico, que são próprios da contemporaneidade de um determinado grupo social [...]. Apesar do discurso liberalizante, a prática do swing não reformula, em seus fundamentos, os papéis sociais considerados adequados a esposas e maridos. Ao contrário, tende inclusive a exacerbá-los - como a superexposição da mulher [...] que reforça o modelo da mulher enquanto objeto passivo do desejo erótico.

Geralmente, existem dois tipos diferentes de relações swingers - as abertas e as fechadas. O swing aberto ocorre quando um casal se envolve com relações sexuais com outro casal no mesmo ambiente, e o swing fechado é quando a troca ocorre em quartos separados. Há 
também swingers suaves e swingers completos que é uma medida utilizada para descrever a quantidade de contato sexual feita entre os parceiros envolvidos, sendo que os suaves se referem à ausência de penetração na relação sexual e os completos fazem sexo com penetração.

O swing é um termo oriundo da língua inglesa, que significa balançar, mover-se livremente. Dados colhidos em pesquisas feitas nas páginas de websites afirmam a hipótese de a origem do swing ser algo inexato, mas que também pode ser comparado às antigas orgias romanas e gregas. Alguns websites arriscam a dizer que a prática foi concebida na década de 60, após a revolução sexual. No entanto, a primeira referência ao swing foi publicada em 1928, nos escritos do autor H. O. Jones, na obra conhecida como "Vidas". Na ocasião a palavra swing foi usada para troca de elementos entre casais, portanto, a prática já era conhecida nos anos 20, de acordo com artigo publicado no site "Prazeres Privados".

A média de idade das pessoas praticantes de swing é trinta anos, de etnia branca e com a educação acima da média (JENKS, 1985). Surgiu durante a $2^{a}$ Guerra Mundial entre pilotos da força aérea estadunidense, pois como a taxa de morte era elevada, caso algum militar fosse morto, outro sujeito cuidaria da esposa. Também existe a relação com a luta pela liberdade sexual na década de 70 e o movimento hippie e sua poligamia.

No Brasil, Fontoura Jr. (2015) identificou que os primeiros anúncios de troca de casais surgiram nos anos 1970 em jornais da cidade do Rio de Janeiro, uma prática ousada e inédita considerando que o país vivia os anos de chumbo da ditadura militar.

De acordo com Orejuela, Piedrahita e Renza (2012) há vários tipos de swinger na comunidade, tais como os ocasionais que não estruturam seu relacionamento baseado no swing; os localizados que praticam com mais frequência que os ocasionais, tendo certo conhecimento da comunidade; e os personalizados, que preferem a pratica de swing em seus relacionamentos mas não abrem totalmente seus gostos e estilo de vida para outras pessoas. Além disso, existem aqueles que declaram abertamente suas preferências sexuais, se relacionam com outras pessoas do mesmo gosto e exercem frequentemente o swing.

Orejuela, Piedrahita e Renza (2012) apontaram em sua revisão de literatura duas questões que norteiam a prática do swing: a lógica masculina por detrás dessa atividade, e que seus praticantes são oriundos das classes média e alta. Também comentaram que os swingers,

apesar de sua prática sexual não convencional que rompe com os conceitos tradicionais de sexualidade, seguem preservando ideais do casal convencional. [...] a novidade é que, pela primeira vez, se pauta no núcleo do casal como unidade relacional e de forma consensual (p. 43). 
Nessa mesma linha, Teixeira (2015) questiona se o swing é uma troca de casais ou uma troca de mulheres. Os argumentos usados pela autora sugerem que essa prática reforça

o modelo androcêntrico de família patriarcal, monogâmica e heterossexual; os homens fazem um falso enaltecimento da mulher no swing, cuja prática está marcada por troca de mulheres, violência simbólica e controle.

Fontoura Jr. (2013, p. 6) explica que, no swing,

por mais que fossem utilizadas partes do discurso de liberação sexual e de igualdade entre homens e mulheres, o fato é que elementos do patriarcalismo, típicos da família nuclear, permaneciam bastante evidentes [...].

O swing sugere uma prática sexual dissidente, no entanto, Weid (2009, p. 108) fala sobre a ambiguidade ou imprecisão na compreensão que dele se tem:

Para alguns, o swing é um mundo machista, de dominação masculina e mulheres submissas. Para outros, uma experiência ousada, libertária e inovadora. Uma tentativa moderna de viver um relacionamento. O que se observa nessas posições é uma necessidade de classificar, de opor, de escolher um lado ou outro.

Existem diversos estigmas em relação às pessoas praticantes do swing, como se estas fossem pessoas libertinas, sadomasoquistas; que não se cuidam; portadoras de doenças sexualmente transmissíveis (DSTs). Um dos motivos para que esse comportamento seja assim rotulado, refere-se aos valores tradicionais morais da sociedade heterossexual. O swing representa rupturas com as formas tradicionais de casais que buscam novas formas de prazer e tem como objetivo o controle da infidelidade, pois toda ação é consentida pelo parceiro.

No entanto, uma observação interessante é que, no swing, homens são heteros e mulheres podem ser bissexuais, fato demonstrado por vários autores (WEID, 2009; VIEIRA, 2013; SILVÉRIO, 2014, dentre outros).

Silveira (2014, p. 20), explica que

quando um casal se declara swinger, fica claro que, de maneira similar a um casamento aberto, se ama apenas uma pessoa, mas o sexo, quando feito com alguém externo ao casal, envolve ambos os cônjuges, seja ele com um terceiro sujeito, ou trocando de parceiros/as simultaneamente com outro casal.

Weid (2010) diz que é o amor ao cônjuge que assinala a fidelidade no swing, e não a relação sexual propriamente dita. É, então, o swing uma prática sexual dissidente? Uma proposta de liberdade sexual ou um espaço que reforça valores e atitudes de dominação escamoteadas por um discurso libertário? 
Há vários sites, fóruns e serviços para a comunidade swing, os quais facilitam os encontros entre casais e o fator "privacidade" é alardeado pelos sites. As propagandas dos sites claramente são focadas em homens heterossexuais, pois pode-se observar apenas imagens de mulheres no plano de fundo. E estudos comprovam que os primeiros passos do casal para um relacionamento liberal geralmente se dão pela vontade do homem. De acordo com a análise de alguns sites, há mais de 30 milhões de usuários, além da existência de aplicativos nos smartphones.

\section{Método}

\section{Participantes}

Foram participantes deste estudo membros de uma comunidade virtual de comportamento sexual liberal que voluntariamente postaram conteúdos na ferramenta Fórum do Website, perfazendo a seguinte amostragem:

Tabela 1 - Perfil das pessoas respondentes do Fórum

Fonte: Elaborado pelos autores (2018)

\begin{tabular}{l|r}
\hline Perfil & Ocorrências \\
\hline Casais & 39 \\
Homens & 11 \\
Mulheres & 10 \\
Outros & 17 \\
TOTAL & 77 \\
\hline
\end{tabular}

Os sujeitos participantes possuíam idade mínima de 18 anos, sendo voluntários não pagos conforme as normas vigentes para execução de estudos com seres humanos no Brasil. No total, há 39 casais, 11 homens, 10 mulheres e 17 classificados como "outros", devido ao "apelido" no site não delimitar um gênero. Houve uma resposta a mais, porque o mesmo usuário publicou suas respostas duas vezes consecutivamente.

Todas as informações foram utilizadas somente com fins de pesquisa, e a identidade dos participantes foi preservada com todo rigor. A coleta de dados foi realizada no período de outubro a novembro de 2018, utilizando-se todas as ocorrências de postagens. 


\section{Ambiente de estudo}

A pesquisa foi realizada no ambiente virtual de fórum de um website de comportamento sexual liberal, sendo que para se ter acesso ao conteúdo das postagens utilizou-se a viabilidade de um dos pesquisadores já ser membro da comunidade.

A ferramenta Fórum é aberta para qualquer membro postar um tópico novo ou interagir nos tópicos já existentes, sendo que a administradora do website monitora rigorosamente o seu conteúdo quanto aos temas e postagens.

No Fórum também há a possibilidade dos membros concordarem ou não com as postagens por meio dos ícones de polegar para cima (que assinala a concordância) e polegar para baixo (afirmando a discordância), além de apresentar a data e a hora da postagem e o perfil do membro que postou, havendo também a possibilidade da postagem ser anônima.

Todo fórum é aberto para os membros interagirem voluntariamente.

\section{Procedimentos}

Para investigar o desânimo das pessoas nas práticas de comportamento sexual liberal, partimos de uma pergunta feita por um dos participantes da plataforma. Como buscávamos deixar os integrantes à vontade e interessados, sugerimos que eles nos dissessem que assunto relacionado à prática do swing deveria ser discutido. Um dos participantes fez a seguinte pergunta: “Alguém por aqui já se sentiu desanimado com o meio liberal? Como reagiu, ou como reagiria?". Assim, direcionamos a conversa na plataforma para colher as informações que utilizaríamos para escrever o presente artigo.

\section{Análise das informações}

Todas as postagens foram organizadas conforme as ocorrências de respostas positivas, negativas ou indiferentes relativas à pergunta inicial do Fórum, além de diagnosticar postagens que desviavam o foco da pergunta.

Além disso, todo o conteúdo foi analisado qualitativamente pelos autores utilizando dizeres dos sujeitos para ilustração das análises, chegando-se às discussões, considerações finais do estudo e formas de intervenção para a temática. 


\section{Resultados}

O fórum obteve 77 postagens de diversos Estados do Brasil, obtendo as seguintes respostas:

Tabela 2 - Categorias referentes às respostas positivas e negativas sobre o desanimo do comportamento sexual liberal do fórum

\begin{tabular}{ll}
\hline Perfil & Casais Homens Mulheres Outros TOTAL \\
\hline Positivo & 30025 \\
Negativo & 30861155 \\
Indiferente & 22004 \\
Outras respostas & 622212 \\
& 76 \\
\hline
\end{tabular}

Um sujeito forneceu duas respostas a esta questão, alterando o valor de $\mathrm{N}$.

Fonte: Elaborado pelos autores (2018)

Podemos observar que a comunidade de comportamento sexual liberal opina que há mais pontos negativos em detrimento de pontos positivos. De acordo com o quadro acima, os casais são os que mais apresentam insatisfação, em seguida, perfis com gênero não identificado, homens e, por fim, mulheres.

Em relação a "outras respostas", alguns casais relataram que frequentam o swing quando há "tesão", não respondendo à pergunta diretamente do site. Os casais que não frequentam mais a comunidade swing estão cansados de pessoas que se fecham em "panelas"; que não respeitam as regras do swing; abordagem invasiva dos outros casais; ciúme; inveja; fofoca; competição, entre outros: “[...] Sinceramente tem entrado muita gente sem noção, que estão liberais naquele momento" - disse um dos participantes fazendo uma crítica às pessoas que não respeitam as regras do swing.

Outro participante do fórum comentou: “[...] além disso, no nosso caso, ainda houve algumas decepções com alguns casais e singles do meio liberal que nos levaram a dar uma boa pausa. Mas agora voltamos, e parece que está melhor, pelo menos em nosso ponto de vista...".

De acordo com o relato de um casal na comunidade, "o swing hoje é comércio. É desrespeito, é uma coisa insana que não se consegue mais definir. O swing hoje, na maioria dos casos, é para comer a mulher dos outros por mera competição. Te como hoje e amanhã não quero saber, nem mais de papo com você". 
Outro praticante apontou a importância da reflexão da prática do swing, ou seja, repensar o motivo real pelo qual se participa do swing: “[...] Se estão sentindo esse ranço, dar um 'tempo' para digerir e repensar como e se é saudável viver o meio... considero essencial..."

Há outros casais que interpretam o swing como uma forma positiva: “[...] estamos no swing desde 2008, aqui no site desde 2009, com nós a cada ano só tem aumentado nosso desejo".

Em relação às pessoas indiferentes ao swing, uma mulher cita "[...] A gente não muda os outros, a gente pode mudar a si próprio..." relatando que não é o meio que desanima, sendo necessário a adaptação do sujeito.

Houve depoimentos confirmando casos de perda de interesse: "Eu conheço casais que o swing virou rotina, e eles acabam perdendo o interesse". Cair na rotina também apareceu como justificativa para o desânimo: "Já vi casais que enjoaram. No começo era novidade, depois caiu na rotina e eles desanimaram".

Uma pessoa afirmou que o swing é um vício e outra reclamou por encontrar sempre as mesmas pessoas e ouvir os mesmos assuntos.

Uma das mulheres afirmou que era muito animada com o swing. Porque com sua prática ela despertou sua sexualidade: "Eu era muito contida. Tive poucos relacionamentos sexuais, $e$ mesmo depois que me casei acho que era meio travada. Mas, com o swing, eu me soltei e hoje já perdi a conta de quantos homens já transei”.

A gestação também é um fator que influencia na participação do swing: "[...Nos] afastamos do meio liberal na fase do planejamento do filho, e agora aos poucos voltando a ativa...".

Um casal mencionou um conjunto de fatores influenciando na diminuição da frequência da prática do swing “[...] As vezes são vários os motivos que levam ao afastamento... problemas familiares (como no nosso caso), a chegada de filhos, a vida estressante por conta do trabalho, entre outros."

\section{Conclusão}

A maioria dos relatos analisados considera o ambiente de swing desanimador, desrespeitoso e invasivo. Vários swingers afirmaram estar desanimados com a comunidade e que os principais motivos são a falta de educação dos participantes devido às propostas grosseiras, a formação de "panelinhas" e a preocupação com quantidades de parceiros sexuais ao invés de qualidade. 
Apesar do meio liberal não se aprisionar em estruturas tradicionalistas, podemos observar por meio dos relatos que é uma comunidade de comportamento sexual liberal que exige respeito e regras de convivência. É uma prática sexual dissidente muitas vezes confundida com um grupo de indivíduos que sempre estão disponíveis para o sexo a qualquer custo e sem regras estabelecidas na comunidade.

O estigma social de que, no swing, "tudo é permitido", pode gerar conflitos entre os swingers, ocasionando desânimo no decorrer do tempo. Portanto, se os sujeitos não se comportam de acordo com as regras estabelecidas na comunidade, pode-se acarretar esses tipos de problemas.

Além disso, fatores externos, como família, diferentes fases da vida e gestação influenciam a falta de interesse na participação na comunidade swing. No fórum, foi dito diversas vezes que os grupos são muito heterogêneos, os quais exigem determinados padrões para a troca de casais, tais como padrão de beleza, status financeiro, opção sexual, dificultando a interação e troca de casais. E os participantes também enfatizam diversas vezes que o respeito é essencial. Apesar do meio ser liberal, as regras existem e precisam ser respeitadas.

\section{REFERÊNCIAS}

CARVALHO, G. C.; VASCONCELOS, E. O desejo do outro como mercado: um estudo sobre gênero e trabalho numa casa de swing em Pernambuco. In: SEMINÁRIO

INTERNACIONAL FAZENDO GÊNERO 10, 2013, Florianópolis. Anais [...]. Florianópolis: Universidade Federal de Santa Catarina, 2013. Disponível em: http://www.fg2013.wwc2017.eventos.dype.com.br/resources/anais/20/1372626230_ARQUIV O_fazendogenerotrabcompl.pdf. Acesso em: 30 nov. 2020.

FONTOURA JR., A. O papel das representações sociais de gênero nos debates sobre a conjugalidade e o swing: a visão das revistas masculinas durante a década de 1970. In: CONGRESSO INTERNACIONAL DE HISTÓRIA, 6., 2013, Maringá. Anais [...]. Maringá: UEM, 2013. Disponível em: http://www.cih.uem.br/anais/2013/trabalhos/238_trabalho.pdf. Acesso em: 30 nov. 2020.

FONTOURA JR., A. Pornotopias conjugais: subjetividades e sexualidades no surgimento do swing no Brasil. Orientadora: Karina Kosicki Bellotti. 2015. 282 f. Dissertação (Mestrado em História) - Universidade Federal do Paraná, Curitiba, 2015.

JANKOWIAK, W. R.; MIXSON, L. H. "I Have His Heart, Swinging Is Just Sex": The ritualization of sex and the rejuvenation of the love bond in an american spouse exchange community. In: JANKOWIAK, W. Intimacies: between love and sex around the world. New York: Columbia University Press, 2008. p. 245-266.

JENKS, R. J. Swinging: a review of the literature. Archives os Sex Behavior, n. 27, p. 507$521,1998$. 
OREJUELA, J. J.; PIEDRAHITA, J. J.; RENZA, F. La práctica/estilo de vida swinger: ¿una práctica social-sexual perversa? Sexualidad, Salud y Sociedad: Revista Lationoamericana, n. 10, p. 37-69, 2012.

SILVEIRA, R. M. Nem tudo é possível e muita coisa é obrigatória: um estudo da prática do swing em Goiânia. Orientador: Camilo Albuquerque de Braz. 2014. 116 f. Dissertação (Mestrado em Antropologia Social) - Universidade Federal de Goiás, Goiânia, 2014.

SILVERIO, M. Gênero, sexualidade e swing: a ressignificação de valores através da troca de casais. Sexualidad, Salud y Sociedad: Revista Lationoamericana, n. 18, p. 111-139, 2014.

TEIXEIRA, M. D. Swing: troca de casais ou troca de mulheres? Orientador: Russell Parry Scott. 2015. 143 f. Dissertação (Mestrado em Sociologia) - Universidade federal de Pernambuco, Recife, 2015.

VIEIRA, S. S. "Nem santa, nem puta": performance de gênero e sexualidade em mulheres praticantes de swing. Orientador: Luís Felipe Rios do Nascimento. 2013. 110 f. Dissertação (Mestrado em Psicologia) - Universidade Federal de Pernambuco, Recife, 2013.

WEID, O. V. D. Masculino e feminino na prática do swing. Sexualidad, Salud y Sociedad: Revista Lationoamericana, n. 3, p. 106-129, 2009.

WEID, O. V. D. Swing: o adultério consentido. Estudos Feministas, Florianópolis, n. 18, p. 789-810, 2010.

WEID, O. V. D. A prática do swing e a dimensão do prazer. Temáticas, Campinas, v. 40, n. 20, p. 35-66, 2012.

\section{Como referenciar este artigo}

GOMEZ, F.; RIBEIRO, P. R. M.; CUSTÓDIO, V. S. Um estudo sobre swing a partir de visões fornecidas por integrantes de uma comunidade virtual de comportamento sexual liberal. Revista on line de Política e Gestão Educacional, Araraquara, v. 24, n. esp. 3, p. 1873-1883, nov. 2020. e-ISSN:1519-9029. DOI: https://doi.org/10.22633/rpge.v24iesp3.14445

Submetido em: 10/01/2020

Revisões requeridas: $20 / 07 / 2020$

Aprovado em: 30/10/2020

Publicado em: 30/11/2020 